\title{
Global Humanitarian Engineering Solutions: A Partnership Between Mercer University and the United Nations Humanitarian Response Depot
}

Dr. Michael F. MacCarthy, Mercer University

Michael MacCarthy is an Assistant Professor of Environmental \& Civil Engineering at Mercer University, where he directs the Engineering for Development program. He has 20 years of experience in water resources engineering, international development, and project management, including nearly a decade living and working in less-developed countries (as a Peace Corps Volunteer in Cameroon, an infrastructure and community development engineer in the Democratic Republic of Congo, Mali, \& Mauritania, and an engineering for development researcher in Madagascar, Bolivia, South Africa, Mozambique, \& the Dominican Republic).

\section{Holly F. Berns, Mercer University}

Holly Berns earned her BSE in mechanical engineering from Mercer University in 2017. She has helped with research regarding water and sanitation hygiene principles (WASH) in Madagascar for Mercer on Mission and innovative supply chain solutions for the World Food Program (e.g. temperature control of SNF - Thermal Shield). She is a past United Nations Intern for UNHRD LAB in Italy.

\section{Mr. Ryan Monty, United Nations Humanitarian Response Depot}

Graduated in May 2017 with a BS in mechanical engineering and a minor in physics. After graduating I took an internship with the United Nations Humanitarian Response Depot (UNHRD) which eventually led to my current position as a engineering consultant for the UNHRD innovation lab.

\section{Miss Mitzi Erin Brett,}

Erin Brett graduated from Mercer University with a Masters and Bachelors in Environmental Engineering. As the first Mercer student to intern with UNHRD in Brindisi, she helped to build the partnership between the two entities. She now works for an Environmental Engineering consulting firm in Orlando, Florida and is a member of Samaritan Purse's Disaster Assistance Response Team (DART) where she was most recently deployed as a WASH Logisitician in Dominica for the Hurricane Maria response.

\section{Mr. Zachary Lewis Martin}

Zachary L. Martin graduated from Mercer University with a Bachelor's degree in Mechanical Engineering as well as a Master's degree in Engineering Management. He has volunteered with Mercer on Mission as an assistant with researching health and water sanitation practices (WASH) for families in eastern Madagascar. He currently works for Burns \& McDonnell, a consulting engineering firm, in the Aviation \& Federal industry.

\section{Ms. Katelyn C.N. Dimopoulos, Mercer University}

Katelyn Dimopoulos was the captain of the Mercer University Division 1 Women's Soccer team and recently earned her BSE in mechanical engineering from Mercer University in 2017. She traveled to Madagascar as part of the Mercer on Mission program to research water and sanitation principles (WASH). She worked as a United Nations intern for the UNHRD Lab in Italy for 3 months and is currently working as an Engineer-In-Training at KCI in Georgia, USA.

\section{Ing. Pietro Sannipoli, United Nations Humanitarian Response Depot}

Pietro Sannipoli is part of the UNHRD Lab since its establishment and he is currently its Project Manager for the Thermal Shield. He also takes part in the relationship with universities providing support in identifying and guiding new projects. Pietro holds his Master's degree in Mechanical Engineering from Alma Mater Studiorum University of Bologna, Italy, where he specialized in Industrial Management and Supply Chain. 


\section{Mr. Nicolas Jerome Messmer \\ Mr. Walid Ibrahim \\ Dr. Scott Schultz, Mercer University}

Dr. Scott Schultz is the Associate Dean and an Associate Professor of Industrial and Systems Engineering in the Department of Industrial Engineering at Mercer University in Macon, Georgia. He also consults at the Mercer Engineering Research Center in Warner Robins, Georgia. He comes from an Industrial background with thirteen years of experience with Ford Motor Co. in Dearborn, MI and Windsor, Ontario and two years of experience at the North Carolina State University Furniture Manufacturing and Management Center. Ten of his years at Ford were as an Information Technology manager in areas of development, installation and support. His primary research and teaching interests are in scheduling, heuristics and process modeling. 


\title{
Global Humanitarian Engineering Solutions: A Partnership between Mercer University and the United Nations Humanitarian Response Depot
}

\author{
Michael F. MacCarthy ${ }^{\mathrm{a}}$, Holly F. Berns ${ }^{\mathrm{a}}$, Ryan A. Monty ${ }^{\mathrm{a}}$, M. Erin Brett ${ }^{\mathrm{a}}$, \\ Katelyn C.N. Dimopoulos ${ }^{a}$, Zachary L. Martin ${ }^{a}$, Pietro Sannipoli ${ }^{b}$, \\ Nicolas J. Messmer ${ }^{b}$, Walid Ibrahim ${ }^{b}$, and Scott R. Schultz ${ }^{a}$ \\ ${ }^{a}$ Mercer University, USA \\ ${ }^{b} U N H R D$, Italy
}

\begin{abstract}
Mercer University's Engineering for Development (E4D) program prepares students to become leaders in implementing sustainable solutions for people and the environment, with an emphasis on improving the lives of under-served populations. The United Nations Humanitarian Response Depot (UNHRD), an entity of the World Food Programme (WFP), is responsible primarily for procurement, prepositioning, and transport of relief non-food items on behalf of the international humanitarian community, for over eighty global organizations. Since early-2015, Mercer's E4D program has been a partner with UNHRD LAB, the research and development lab that focuses on providing better solutions to UNHRD and its partners, specifically to improve logistics support equipment and provide solutions for reducing waste from relief item packaging.

This paper describes: (1) background on UNHRD and Mercer's E4D program, (2) the initiation and development of the Mercer-UNHRD partnership, (3) key ways in which the partnership is advancing interests both for Mercer's engineering students and UNHRD, including through student research and design projects, (4) how UNHRD-Mercer research topics are being used to pique students' interest while they learn fundamental engineering concepts, and (5) future plans to grow the partnership.
\end{abstract}

\section{Introduction and Background}

The Mercer University School of Engineering (MUSE) has a unique partnership agreement with the United Nations Humanitarian Response Depot (UNHRD), since early-2015. This partnership focuses on providing better solutions to UNHRD and its over eighty partner organizations in the global humanitarian sector.

\section{United Nations Humanitarian Response Depot}

UNHRD, part of the Supply Chain Division of the United Nations World Food Programme (WFP), is a network of six strategically located depots that procures, stores, and transports emergency supplies on behalf of the global humanitarian community. These depots are located in Panama, Italy, the Canary Islands (Spain), Ghana, United Arab Emirates, and Malaysia (Figure 1). UNHRD focuses on emergency preparedness and response, and enables the strategic stockpiling of relief items and equipment for over eighty partners, which include UN agencies, 
governmental and non-governmental organizations. The depots provide a full range of comprehensive supply-chain solutions ${ }^{1}$.

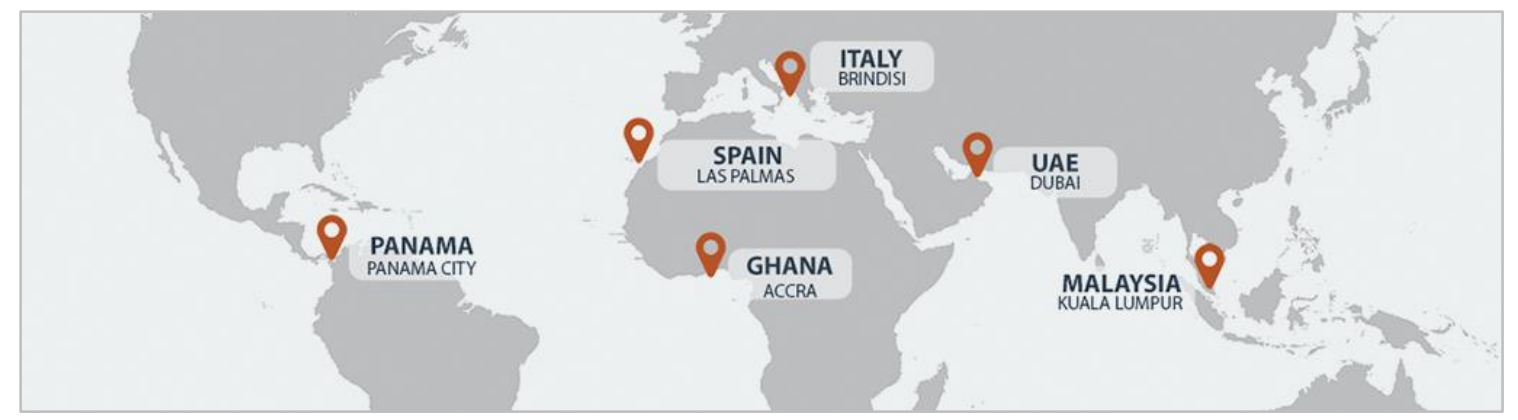

Figure 1: United Nations Humanitarian Response Depot locations

Housed within UNHRD is the lab, UNHRD LAB, located in Brindisi, Italy. UNHRD LAB is a research and development unit that reviews, optimizes and tests products used in humanitarian settings, as well as helps develop innovative logistics solutions in humanitarian operations' supply chain ${ }^{1}$.

\section{Engineering for Development at Mercer University}

Mercer University's Engineering for Development program (E4D - e4d.mercer.edu) provides students with the appropriate skills to work as engineering professionals in the humanitarian and development sectors, both internationally and domestically. E4D offers classes, an undergraduate minor, and a graduate concentration in Engineering for Development, to students in all engineering specialties. The focus of the E4D courses/curriculum is sustainable solutions for people and the environment, with an emphasis on improving the lives of under-served populations $^{2}$. In addition to on-campus courses, students pursuing an E4D minor must travel abroad to a developing community and participate in a practical hands-on humanitarian or development project. Recent projects have been in the Dominican Republic (water, sanitation, and indoor air), Ecuador (environmental health solutions for small-scale gold mining communities), Vietnam (low-cost prosthetics), South Korea (technical training of North Korean refugees), Kenya (drinking water), and Madagascar (drinking water and sanitation).

As part of their partnership agreement, MUSE and WFP have collaborated through UNHRD LAB in: designing and developing relief items and logistics solutions for the supply chain, focusing on cost-effective green technologies and on reducing packaging waste (thus enhancing efforts in emergency preparedness planning and response operations); and sharing knowledge and building capacities.

\section{The Mercer Partnership with UNHRD}

The unique partnership between MUSE and UNHRD has grown since late-2014, as described below by academic calendar year.

2014-2015. The MUSE collaboration with UNHRD began with initial conversations between UNHRD LAB management and MUSE faculty in fall of 2014. UNHRD LAB was interested in 
strategically growing collaborations with select universities to advance the lab's work, and MUSE had just recently started the E4D program. Both parties soon agreed that there was mutual value in working together, to advance the development of activities that could benefit the global humanitarian community while at the same time providing experiences for students and faculty that could enhance their learning and teaching. Following brainstorming of numerous potential activities to further the collaboration, a MUSE-UNHRD partnership agreement was signed between Mercer University and WFP in early-2015.

2015-2016. The MUSE-UNHRD partnership blossomed once the initial Mercer intern, an environmental engineering master's student, started work at UNHRD LAB in Brindisi in fall of 2015. Prior to starting as a United Nations Intern with UNHRD, she had spent five years as an engineering student at Mercer (for undergraduate and graduate studies), during which time she was involved in research, design, and service at various levels (e.g. freshman engineering design, international research and service work in Kenya and Uganda, engineering honors research, Senior Design, and master's thesis). Thus, she had a strong understanding of the technical and service-related research capabilities of MUSE students and faculty. Spending 9 months working at UNHRD LAB allowed her to be involved in numerous lab projects while also acting as the liaison between other UNHRD staff and MUSE faculty and students for the development of research and design projects. She was also instrumental in setting up future internships for Mercer engineering students. Near the end of her 9-month internship, in June 2016, 3 Mercer faculty members visited WFP headquarters in Rome and UNHRD-Brindisi (Figure 2) to work with the lab team, assessing how the partnership had progressed and planning activities for the upcoming year.

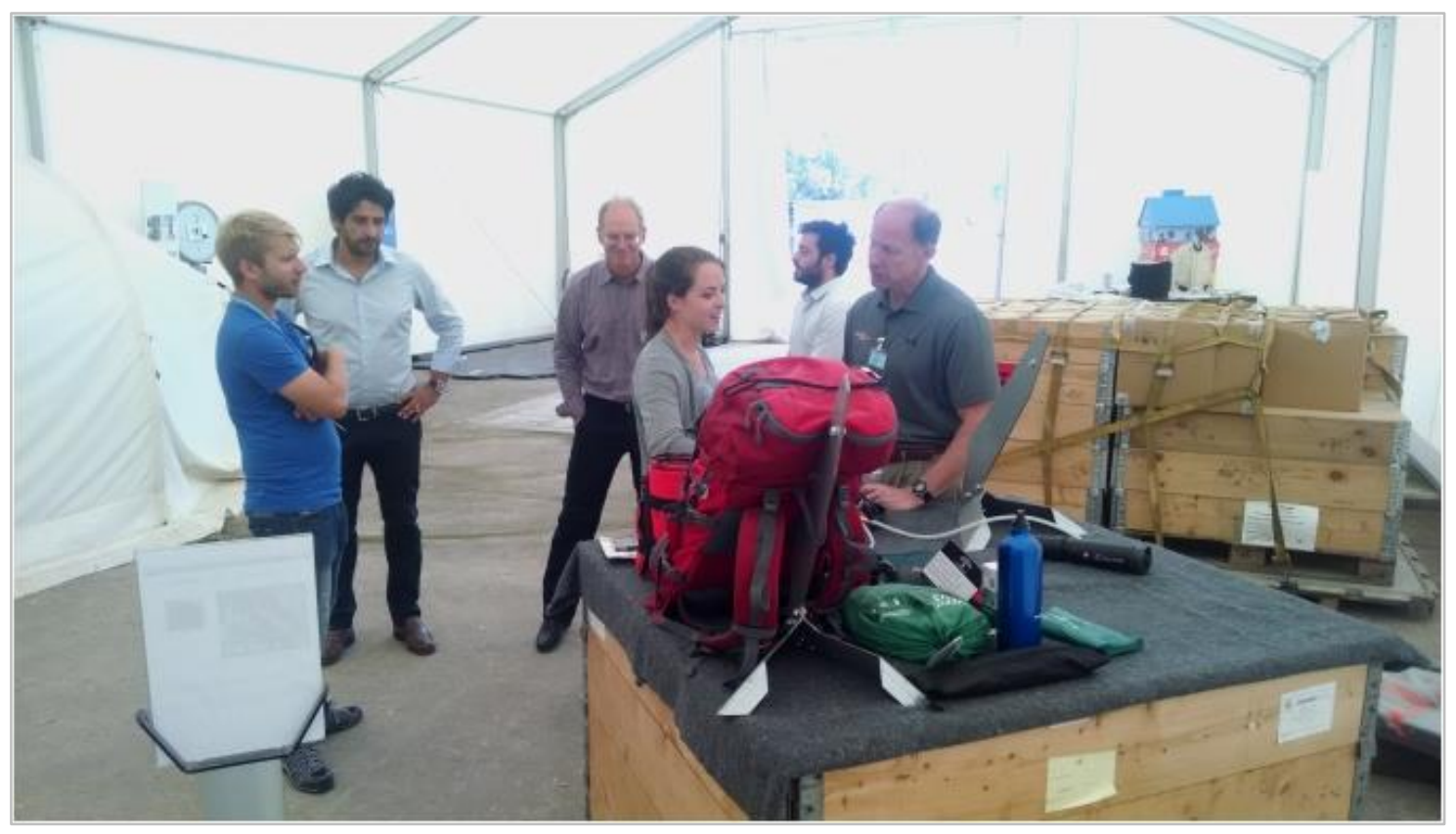

Figure 2: Mercer-UNHRD 2015-2016 intern leads Mercer faculty and UNHRD staff on a tour of humanitarian products displayed at UNHRD-Brindisi. 
2016-2017. The first MUSE-UNHRD Senior Design project officially started in the fall of 2016. This project consisted of the design, construction, and testing of a passive insulation solution to keep supplementary nutritious foods from over-heating during transport and storage. The success of this project led to the opportunity for 3 of the team members to serve as interns with UNHRD LAB. These 3 students began their service as interns with UNHRD LAB in Brindisi in June 2017. Their primary activities included the further development of the passive insulation solution product and liaising with the new (2017-2018) MUSE Senior Design team working on a UNHRD project. Two Mercer faculty members made a support visit to UNHRD-Brindisi in July 2017 to help advance plans for the following year.

2017-2018. Since fall of 2017, a new MUSE-UNHRD Senior Design project has been carried out by a team of two Mercer industrial engineering students and one Mercer industrial design and management student. This project focuses on assessing and developing possibilities to reduce packaging waste used for the most common humanitarian items sent to the field. One 2017 Mercer-UNHRD intern completed her internship with UNHRD in August 2017, while the other two continued their internships until December 2017. The fourth member of the 2016-2017 Senior Design project team has been working part-time during his graduate studies to support the MUSE-UNHRD partnership on campus. In February 2018, one of the 2017 MUSE-UNHRD interns returned to Italy to continue work with UNHRD LAB as a contract employee to further develop the passive insulation solution.

\section{MUSE-UNHRD Internships}

Mercer engineering students had the possibility to intern at UNHRD LAB, putting into practice their theoretical knowledge during a real-world work experience in the humanitarian sector. Thanks to these engineering students, UNHRD LAB benefitted from engineering support for its mission.

The lab is located at UNHRD's hub in Brindisi, Italy. Its primary focus is to liaise with partners' humanitarian personnel in the field to review, optimize and test relief items and support equipment. In collaboration with academia and the private sector, the lab engages in efforts to improve logistics support equipment and provide solutions for reducing waste from relief item packaging. It also sets new specifications for field items based on partners' special requirements, and provides guidance in designing and developing new products.

Thus far, 4 Mercer engineering students have interned at UNHRD LAB in Brindisi. While supporting the engineering mission of the lab, these students also obtained the eye-opening experience of what humanitarian relief entails, seeing UNHRD provide support to the Ebola crisis in West Africa in 2016, the escalating relief efforts in Syria during 2017, etc. It would be difficult to duplicate this experience in a classroom setting. 


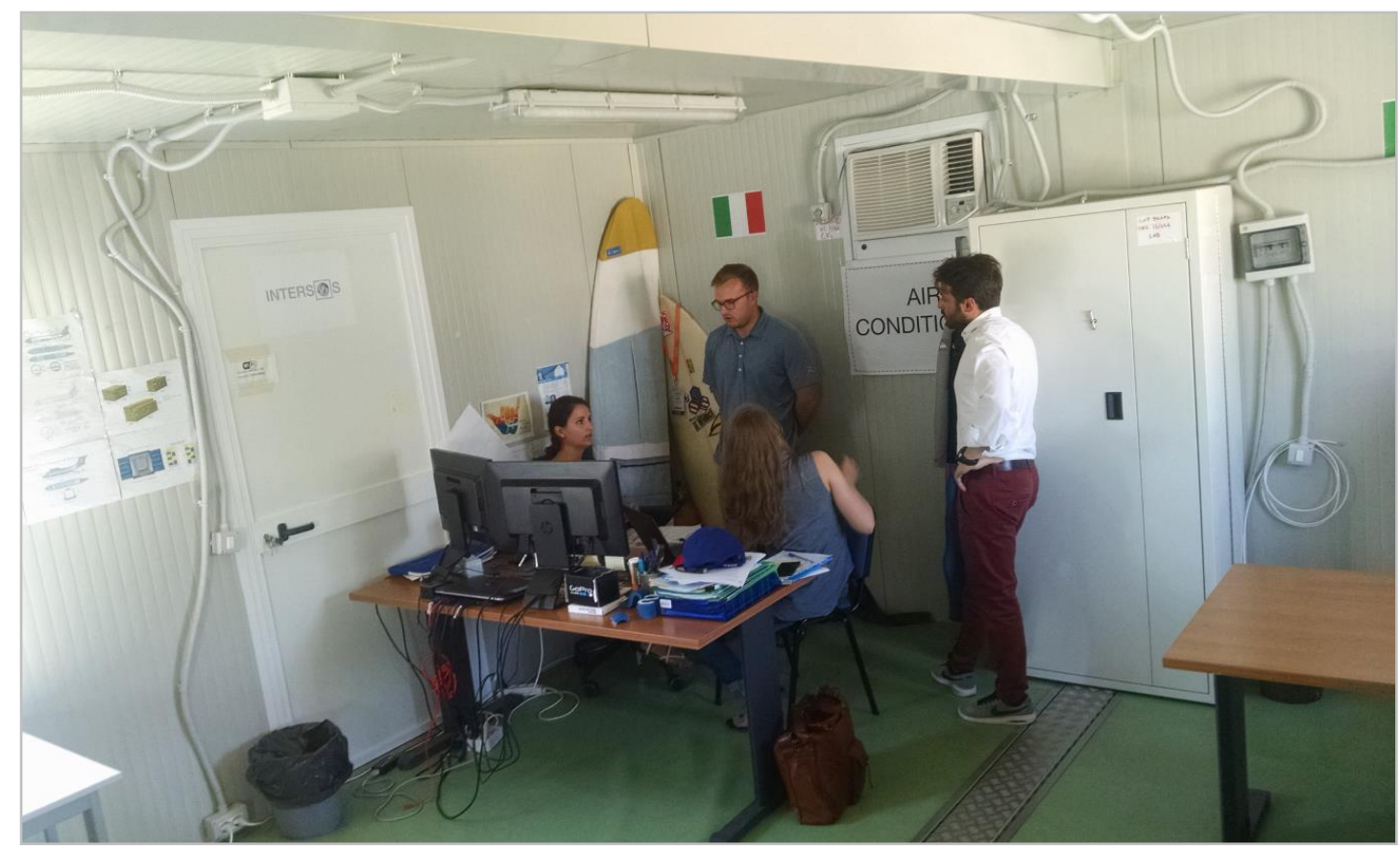

Figure 3: 2017 Mercer United Nations Interns discuss a project with the UNHRD LAB team leader. Based in Brindisi, Italy, UNHRD LAB works to provide the best solutions for the supply chain within the humanitarian community.

\section{MUSE-UNHRD Design Projects}

Another goal of the partnership with UNHRD is for Mercer students to provide innovative designs to meet needs of the global humanitarian community. The MUSE-UNHRD partnership sponsored its first design project in the 2016-17 academic year.

UNHRD proposed a project to MUSE with the intention of having a group of students create an all-encompassing solution to protect specialized nutritious foods (SNF) throughout the shipping process. SNF are nutrient-dense foods that are shipped to humanitarian crises globally in order to treat malnutrition. Because the nutrients in SNF begin to degrade at temperatures above 30 degrees Celsius (86 degrees Fahrenheit), UNHRD requested that the shipping solution be capable of keeping SNF below this temperature threshold.

For such an extensive project, the best fit within MUSE's curriculum is Senior Design. MUSE requires every senior engineering student to complete a two-semester capstone design course. Senior Design projects allow teams of 3 to 4 students to apply their engineering knowledge in a real-world setting prior to graduation. The student teams collaborate to design, build, and test an engineered product under faculty supervision. Faculty serve as technical advisors to the student teams and are available to help offer specific technical advice to students while promoting learner autonomy. In addition to the engineering concepts being considered, students must also take into account safety, economic, environmental, and ethical concerns. These Senior Design projects are completed for a real-world client, giving students an opportunity to experience engineering challenges that parallel those in industry. 
During the 2016-17 school year, a team of consisting of four mechanical engineering students advised by three faculty technical advisors and a faculty manager undertook this UNHRD project, which ultimately became known as the Thermal Shield project.

\section{Thermal Shield Senior Design Project}

Senior Design is a thorough engineering education-experience. Students work on a design project and attend bi-weekly lectures. The lecture portion of this course is taught by an engineering professor who serves as each team's manager. This professor speaks on a variety of topics (e.g. ethics, patents, standards, design selection, project management, etc.) which are all topics to be addressed within each Senior Design project. He/she also functions as the grader for all presentations, papers, and other assignments related to Senior Design.

The course is structured around a number of submission due dates throughout each semester. In total, each team is responsible for submitting a project selection form, budget form, proposal, patent review, preliminary design review (PDR), test plans, critical design review (CDR), and peer evaluation form. In addition to these documents, teams must complete multiple team progress report presentations and oral presentations of the PDR and CDR. Client meetings, technical advising meetings, and individual team meetings are also mandatory, with these meetings being set up by each individual team according to their availability. Centering Senior Design around due dates allows students to have structured autonomy - a day-to-day freedom with monthly deadlines.

Senior Design proves to be a thorough engineering education because each design project incorporates multiple engineering principles (i.e. design, construction, testing, and analysis). While each project may relate to a different topic/field of engineering, every project scope includes fundamental engineering topics and processes, as was the case with the Thermal Shield Project.

Prior to the start of the first semester of Senior Design (in a zero-credit hour 'Intro' course), the student team working on the Thermal Shield began the project by performing market research and brainstorming. At the beginning of the first semester of Senior Design, the team submitted a project proposal to the Mercer faculty advisors in order to receive feedback on pursuing the project with an adapted insulated-pallet-cover design. Once this proposal was approved, the students performed a feasibility and merit analysis to determine which design would best meet the project specifications. After the design was selected, the student team wrote a PDR that contained ample theoretical calculations and thermal analyses to prove the design's capabilities. They presented their findings to the Italy-based UNHRD LAB team in a Skype PDR presentation and gave another PDR presentation to MUSE students and faculty. Team progress report presentations, a budget form, and other Senior Design related course work were simultaneously completed by the student team.

Figure 4 illustrates the temperature analysis of the SNF with and without the Thermal Shield over a 30-day period as the ambient temperature fluctuates within an ocean container. This temperature distribution is valuable because it consistently reaches high temperatures $\left(40^{\circ} \mathrm{C}\right.$ and above) for multiple days in a row. The Thermal Shield is able to keep the SNF below $30^{\circ} \mathrm{C}$ during the entire 30 days despite the high ambient temperatures acting on the Thermal Shield. 
Although the Thermal Shield is able to keep the SNF temperature below $30^{\circ} \mathrm{C}$, the $\mathrm{SNF}$ boxes without the Thermal Shield reach temperatures over $30^{\circ} \mathrm{C}$ for around 10 days.

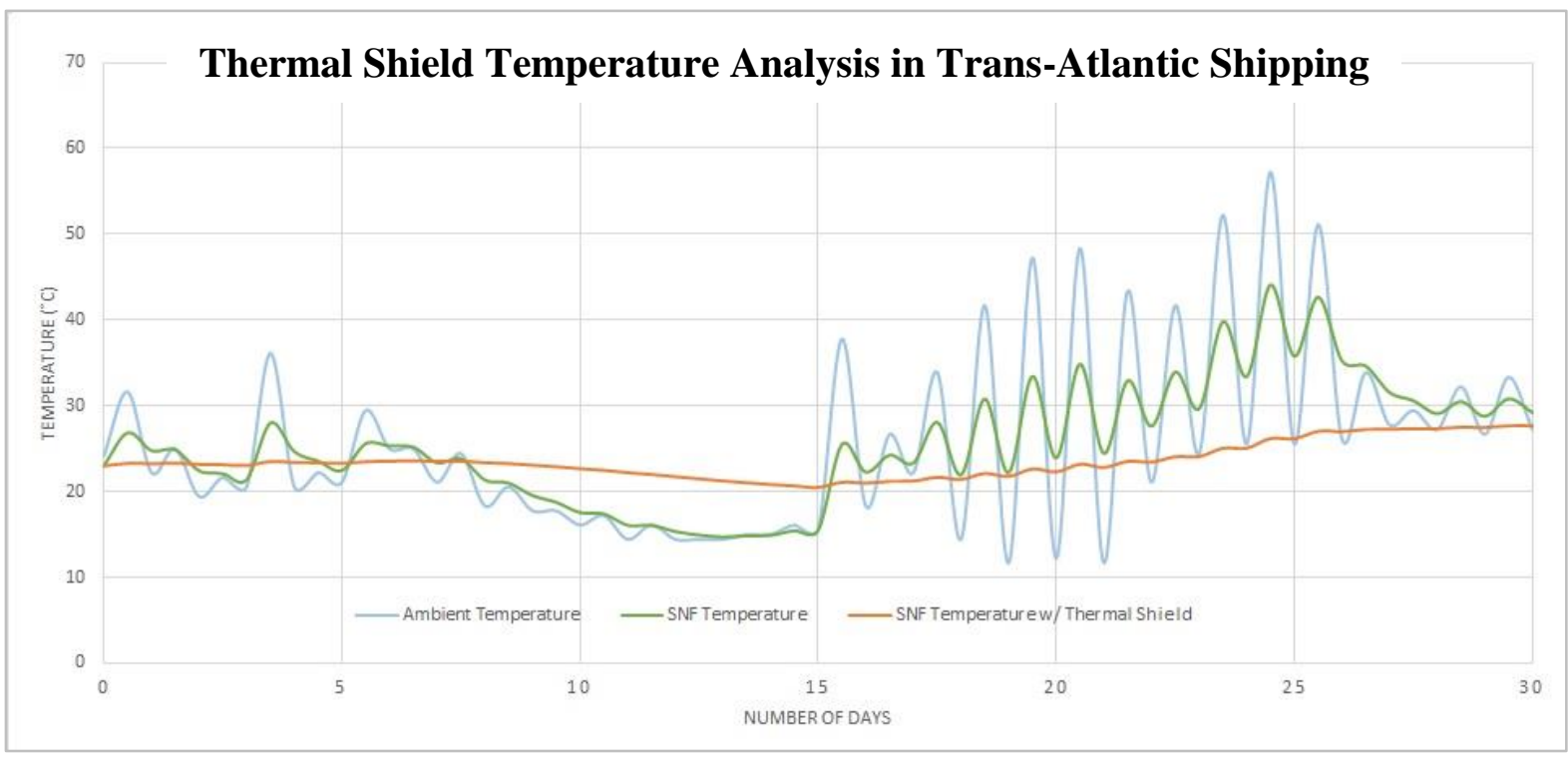

Figure 4: Temperature analysis of the SNF with and without the Thermal Shield over a 30-day period as the ambient temperature fluctuates within an ocean container

In the second semester of Senior Design, the student team proceeded with material procurement, construction, testing, and analysis for a scaled prototype. The Thermal Shield scaled prototype was constructed entirely by the students with the use of a sewing machine and other common tools. Figure 5 illustrates the Thermal Shield flattened and assembled.
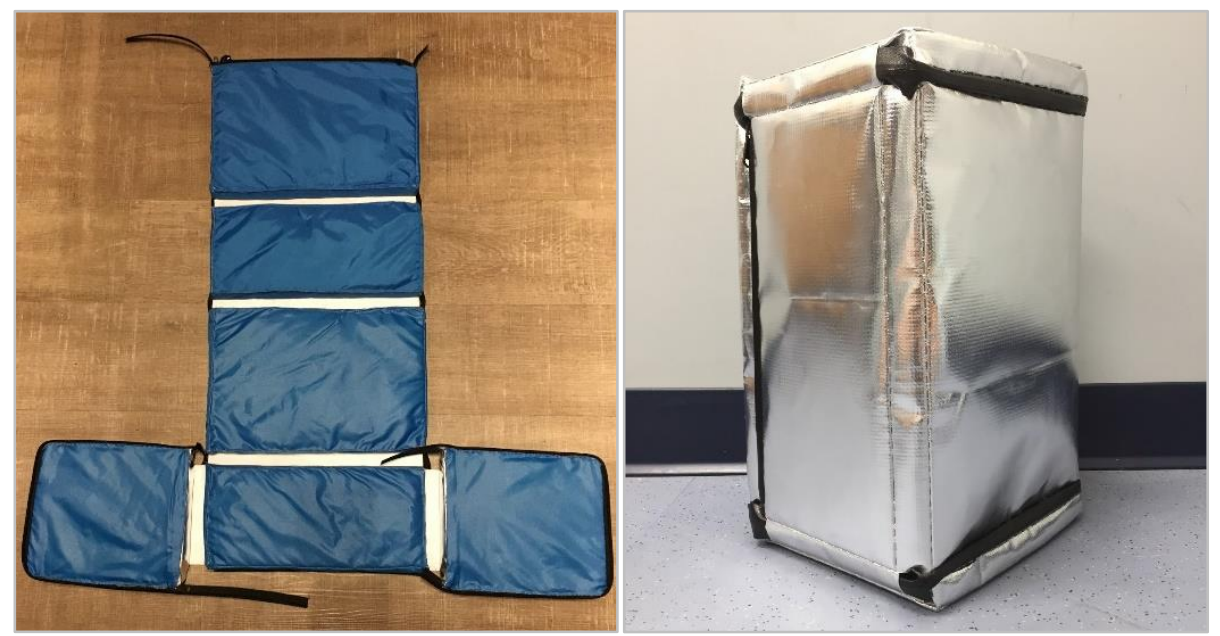

Figure 5: Photos that illustrate the completed scaled prototype Thermal Shield. The photo on the left depicts the Thermal Shield in its unzipped flattened orientation while the photo on the right shows the Thermal Shield assembled, zipped, and ready for shipment ${ }^{3}$. 
Three tests were performed on the scaled prototype in order to prove the Thermal Shield's performance capabilities, resistance to the environment, and durability. After testing and analyses, the students wrote and submitted a CDR and presented their findings during two presentations - one CDR presentation to MUSE students and faculty and one video conference presentation to the UNHRD LAB team. The Figure 6 graph represents the temperature versus time comparison of a thermocouple placed within the center of the food mass, with and without the Thermal Shield over three cycles. Each cycle is comprised of two 12-hour periods, where the first period was held at roughly $55^{\circ} \mathrm{C}$, while the second period was held at roughly $23^{\circ} \mathrm{C}$. The data that was collected over these three cycles is represented by the solid lines on the graph. After the third cycle, a prediction model was created to simulate the temperature increase for the data with and without the Thermal Shield. This is represented by the dashed lines on the graph. The ambient temperatures for the predicted model were held at $55^{\circ} \mathrm{C}$ and $22.5^{\circ} \mathrm{C}$ for 12 -hour periods.

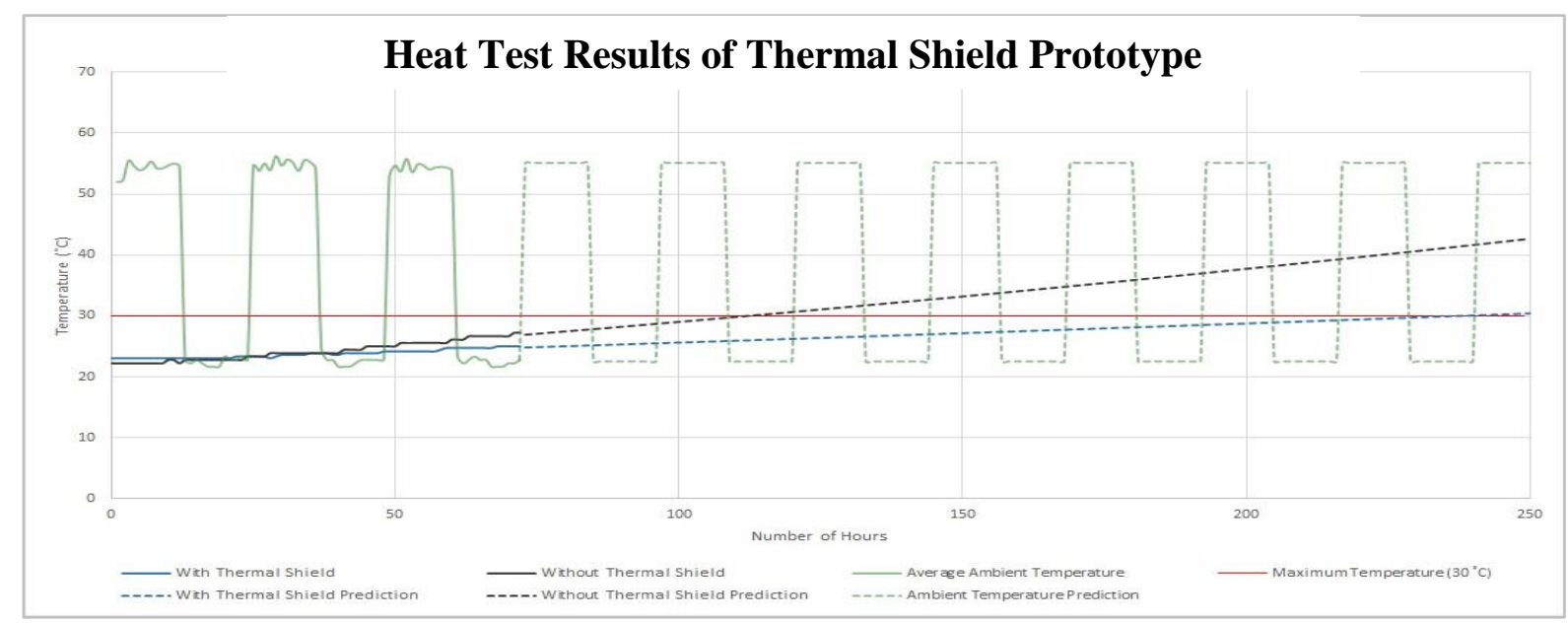

Figure 6: Thermal Shield prototype heat test results

\section{Additional Project Benefits}

In addition to the educational value of Senior Design, the UNHRD Thermal Shield project provided several other benefits. First, three of the team members had the opportunity to work as interns for UNHRD LAB in Brindisi, Italy. The students continue the work of the team on the Thermal Shield by designing a full-scale prototype, and related tests on efficiency and durability were planned. As a major goal of the Mercer-WFP partnership, the teams of MUSE and UNHRD LAB continued the development of the Thermal Shield in order to get the product market-ready. In particular, these internships provided the students involved with an extended educational and professional experience in an international setting.

Another benefit is that the Thermal Shield project can be used as a specific topic within both an upper-level heat transfer course and an engineering economy class. For heat transfer, the Thermal Shield provides a comprehensive example of a passive cooling device. Heat transfer topics such as lumped capacitance, 1-D transient systems, radiation, irradiation, convection, and thermal resistance are all involved. Additionally, the processes of design, prototyping, and 
testing are incorporated in the Thermal Shield Project. This real-world comprehensive heat transfer example comes from a worldwide humanitarian need, proving to students that the effects of heat transfer can have a profound impact on society. In addition to heat transfer, the Thermal Shield could be an example used in an upper-level engineering economy class and/or an upperlevel supply chain course. Because the Thermal Shield is constructed for worldwide product shipment, it has a global supply chain. Each aspect of this supply chain could be analyzed as well as the product's procurement protocol, manufacturing methods, and international impact. Since the Thermal Shield is a product idea initiated by UNHRD/WFP, it is a typical real-world example that can be used in the classroom to demonstrate to students what occurs in industry. The Thermal Shield project is more than a Senior Design project; it is a great example for continued education to be built upon.

Finally, a course module is being developed for the E4D program based on the knowledge gained from the Mercer-UNHRD partnership, including the Senior Design projects and internships. This module, taught in one of the core courses for the E4D undergraduate minor and graduate concentration, covers humanitarian logistics and appropriate technologies for the humanitarian sector (including the Thermal Shield), and includes case studies of recent/current humanitarian crises.

\section{Senior Design - A Team's Perspective of Educational Outcomes}

After completing the Thermal Shield project, the Senior Design team members, all of whom are co-authors on this publication, were asked to give their perspective on their overall experience.

MUSE's Senior Design course adds to each engineer's learning experience by creating a professional work-like experience. First, the projects themselves come from a demand for innovation, not just an interest or conventional idea for an encapsulating project. Generally, the projects come from one of two places. Most commonly, MUSE faculty (along with the connections they have made in their previous endeavors and continued careers) generate potential projects that will push students to innovate and create new solutions for real-world problems. Alternatively, students have the option of finding their own project to work on by contacting companies for industry-based projects. As long as the project is approved by the students' advising professor(s), the project can be pursued. The requirement of finding actual value in the project, outside of being a grade, is an essential start to creating a real work-like experience.

Moving forward, the engineering teams are continuously held accountable for the work they are accomplishing. In many cases, the client the team is providing a service for is not a professor or member of the faculty but rather a member of the professional world who is outsourcing their work to the student team. This means that the solutions created by the students need to be implementable and intended to be taken beyond the year-long course.

The responsibility placed on the students gives a real sense of what future work outside of college will be like. Working as a part of a team, each individual's responsibilities become increased yet more focused. Aspects of team-work, technical writing, time-management, communication, project management, and leadership are all incorporated in this course. Unlike the normal experience of engineering school up to this point, where students take many courses 
with various areas of study and work, Senior Design puts one big challenge in front of a team. Tasks need to be defined and effectively split up among team members. This division of work is meant to play into the strengths of each individual within the team, but the act of dividing tasks is ultimately left to the autonomy of the team. Deadlines for work accomplished must be agreed upon by the team and additional project scheduling must be completed by each team. Outside of the few major deadlines and occasional meetings with advisors and clients, the planning and scheduling for completing work is up to each team to agree upon. This level of autonomy tests the communication skills of the team unlike anything students have previously encountered in college. This aspect of Senior Design is perhaps the most important factor in determining whether a project will succeed or fail. Each member of the team needs to be active in the collective communication of the group so that things can be discussed and courses of action can be agreed upon. For some, this is not an easy or comfortable thing to do.

Parallel to a real work environment, there are times in which someone in the group needs to step into a leadership role and direct the conversation to be inclusive and open in order to involve everyone. However, there cannot be just one leading member of the group during the entirety of the Senior Design process. This role needs to be fluid, incorporating give and take amongst all members of the team. Each person on the team has different responsibilities and parts of the project that they are in charge of, so as the project progresses so does everyone's role on the team. Again this is very similar to a real working environment. While a normal school project or capstone class could easily be dominated by one person doing all of the work and making all of the decisions, in a company or organization there is simply too much responsibility and work for a real team dynamic to not exist.

The student team members found that working in the Senior Design course taught them a lot about working in a more realistic, more professional, engineering setting. The scale of the project made them plan on both the macro and micro scale. Large goals were planned to be on-time with deadlines and presentations, but these milestones were only achieved by consistently meeting and agreeing on daily and weekly plans of action. Assignments were divided, giving each member a specific area of focus/expertise. When the project moved to an individual focus, the team member responsible was then asked to be prepared and lead the discussion. There was a level of trust and accountability that needed to be maintained throughout the project. If one member of the team had consistently failed to meet expectations, other team members would have been forced to pick up their slack creating a lower quality of overall work. This scale of a project, with its impactful goal of helping to improve the logistics of humanitarian efforts around the world, was about as serious and close to a real professional working experience that any senior engineering students could have experienced in college. The Senior Design team expressed that the experience was the perfect send-off into the working-world for them.

\section{Acknowledgments}

The authors wish to thank Loren Sumner and Dorina Mihut of Mercer University, Jonas Bergmann-Paulsen and Davorka Garagic (formerly of WFP), and Marta Laurienzo of WFP for their support in this work. 


\section{References}

1 "Supporting the Humanitarian Community." UNHRD, unhrd.org/.

2 MacCarthy, M. and L.A. Lackey (2016) "Engineering for Development (E4D) at Mercer University" Building Your Future in Engineering, Georgia Engineer Magazine, August 2016, pp 28-29.

3 Berns, H., Dimopoulos, K., Martin, Z. and Monty, R. (2017) “ASEE Thermal Shield Poster”, ASEE SE Conference, Florida, March 2018.

\section{Michael F. MacCarthy}

Dr. Michael MacCarthy is an Assistant Professor of Environmental \& Civil Engineering at Mercer University, where he directs the Engineering for Development program (e4d.mercer.edu). He received his Ph.D. in Civil Engineering (Water Resources concentration) from the University of South Florida. He has twenty 20 years of experience in water resources engineering, international development, and project management, including nearly a decade living and working in less-developed countries. Mike's research interests include global WASH (Water, indoor Air, Sanitation, \& Hygiene), low-cost technologies, self-supply, and social marketing. He teaches courses in engineering for development and water resources engineering.

\section{Holly F. Berns}

Holly Berns earned her BSE (Bachelor of Science in Engineering) in mechanical engineering from Mercer University in 2017. She has helped with research regarding water and sanitation hygiene principles (WASH) in Madagascar for Mercer on Mission and innovative supply chain solutions for the World Food Program (e.g. temperature control of SNF - Thermal Shield). She served as a United Nations Intern for UNHRD LAB in Italy in 2017.

\section{Ryan A. Monty}

Ryan Monty earned his BSE in mechanical engineering and a minor in physics from Mercer University in 2017. He previously worked under the chair of the mechanical engineering department at Mercer University organizing academic scholarships for incoming STEM students and consulting with professors on ongoing projects. After serving as a United Nations Intern for UNHRD LAB in Italy in 2017, he now continues work for them as a contract employee.

\section{Erin Brett}

Erin Brett graduated from Mercer University with Master's and Bachelor's degrees in Environmental Engineering. As the first Mercer student to intern with UNHRD in Brindisi, she helped to build the partnership between the two entities. She now works for an Environmental Engineering consulting firm in Orlando, Florida and is a member of Samaritan Purse's Disaster Assistance Response Team (DART), where she was most recently deployed as a WASH Logistician in Dominica for the Hurricane Maria response.

\section{Katelyn C. N. Dimopoulos}

Katelyn Dimopoulos was captain of the Mercer University Division 1 Women's Soccer team and recently earned her BSE in mechanical engineering from Mercer University in 2017. She travelled to Madagascar as part of the Mercer on Mission program to research water and 
sanitation principles (WASH). She worked as a United Nations Intern for UNHRD LAB in Italy for 3 months, and is currently working as an Engineer-In-Training at KCI in Georgia, USA.

\section{Zachary L. Martin}

Zachary L. Martin graduated from Mercer University with a Bachelor's degree in Mechanical Engineering as well as a Master's degree in Engineering Management. He has volunteered with Mercer on Mission as an assistant researching household water and sanitation (WASH) conditions in eastern Madagascar. He currently works for Burns \& McDonnell, a consulting engineering firm, in the Aviation \& Federal industry.

\section{Pietro Sannipoli}

Pietro Sannipoli is part of UNHRD LAB since its establishment and he is currently its Project Manager for the Thermal Shield. He also takes part in the relationship with universities providing support in identifying and guiding new projects. Pietro holds his Master's degree in Mechanical Engineering from Alma Mater Studiorum University of Bologna, Italy, where he specialized in Industrial Management and Supply Chain.

\section{Nicolas J. Messmer}

Nicolas Messmer holds over 20 years' experience in the field of logistics, procurement and supply chains; program management; and cluster coordination in the humanitarian sector. His diverse professional experience is rooted in both humanitarian emergency and development contexts throughout Africa, Asia, Latin America and the Middle East. During this time, he has worked with several international development and humanitarian aid organizations, notably Doctors Without Borders (MSF) and the United Nations World Food Programme (WFP). He has provided support operations and cluster coordination to logistical operations, as well as strategic thinking direction to multi-sectoral programming, as a program manager and advisor. In an advisory role, he established WFP's United Nations Humanitarian Response Depot (UNHRD's) first research and development unit, UNHRD LAB, focused on innovation and technology for the testing of existing items and products, along with the development of new innovations. He also provided representation of UNHRD LAB with donors, academic institutions, suppliers and technical conferences / forums, including serving as the technical lead for UAVs, drones, and innovative technologies.

\section{Walid Ibrahim}

\section{Scott R. Schultz}

Dr. Scott Schultz is the Associate Dean and an Associate Professor of Industrial and Systems Engineering in the Department of Industrial Engineering at Mercer University. He also consults at the Mercer Engineering Research Center in Warner Robins, Georgia. He comes from an Industrial background with thirteen years of experience with Ford Motor Co. in Dearborn, MI and Windsor, Ontario and two years of experience at the North Carolina State University Furniture Manufacturing and Management Center. Ten of his years at Ford were as an Information Technology manager in areas of development, installation and support. His primary research and teaching interests are in scheduling, heuristics and process modeling. 